\title{
Normal gözlerde yaş ve cinsiyetin retina kalınlığına etkisi
}

\author{
Effect of age and sex on retinal thickness in normal eyes
}

\author{
Gülin Tuğba Ongun
}

Gönderilme tarihi:29.05.2018

Kabul tarihi:08.08.2018

\section{Özet}

Amaç: Bu çalışmanın amacı normal gözlerde makula kalınlığının ve peripapiller retinal sinir lifi kalınlığının yaş ve cinsiyet ile ilişkisini optik koherans tomografi ile değerlendirmektir.

Gereç ve yöntem: Çalışmaya 2017 Şubat ve 2018 Ocak tarihleri arası Burdur Devlet Hastanesi Göz Hastalıkları Kliniği'ne başvuran sağlıklı 500 kişi alındı. Çalışmaya herhangi bir göz hastalığı olmayan ve daha önce oküler cerrahi öyküsü, sistemik hastalığı olmayan 18-100 yaş arası bireyler dahil edildi. Poliklinik kayıtlarından; düzeltilmiş en iyi görme keskinliği Snellen eşeline göre 20/20, göz içi basıncı 10-20 mmhg, refraktif değerleri +/- 3,00 dioptri olan gözler ve optik koherans tomografi sonuçları alındı. Makula kalınlığını yaş grupları arasında karşılaştırmada ve cinsiyet ilişkili değişiklikleri analiz etmek ve sektörler arasındaki retina kalınlıklarını karşılaştırılmak için bağımsız örneklem t testi kullanıldı. Santral foveal kalınlıkta yaş gruplarında cinsiyet farklıııklarını karşılaştırmak için iki yönlü varyans analizi kullanıldı.

Bulgular: Çalışmaya alınan 500 kişinin 247'si kadın 253'ü erkekti. Santral foveal kalınlık erkeklerde kadınlara göre anlamlı olarak daha kalın saptandı $(p=0.001)$. Yaş artışı ile birlikte santral fovea kalınlığında anlamlı bir değişiklik saptanmadı $(p=0.068)$. Yaş ve cinsiyet grupları arasında; total peripapiller retina sinir lifi tabakası kalınlığı, üst ve alt kadran retinal sinir lifi tabakası kalınlığı, optik disk çukurluk ve disk alanları ile çukurluk/disk oranında da anlamlı bir değişiklik görülmemiştir $(p=0.001)$.

Sonuç: Retinal kalınlıklarında yaş ve cinsiyete bağlı olarak anlamlı değişiklikler görülmüştür. Yaşla birlikte santral fovea kalınlığında anlamlı bir değişiklik saptanmazken erkeklerde kadınlara göre anlamlı olarak daha kalın saptanmıştır. Perisantral halkada temporal ve üst sektör kalınlıklarında yaşa bağlı anlamlı incelme görülmüştür. Bu nedenle, bu bulgular hem sistemik hem de retinal hastalıklarla ilişkili retinal tabaka kalınlığını analiz ederken dikkate alınmalıdır.

Anahtar Kelimeler: Optik koherans tomografi, yaş, cinsiyet.

Ongun GT. Normal gözlerde yaş ve cinsiyetin retina tabakaları kalınlığına etkisi. Pam Tıp Derg 2019;12:41-48.

\begin{abstract}
Purpose: The aim of this study is to evaluate the effect of sex and age on macular thickness and peripapillary retinal nerve fiber thickness in normal population with optical coherence tomography.

Materials and methods: Mediacal records of 500 healthy people aged 18-100 who applied to the Burdur State Hospital Ophthalmology Clinic between February 2017 and January 2018 were enrolled. Exclusion criterias were having any eye disease or ocular surgery history and systemic disease.Best corrected visual acuity of $20 / 20$ according to Snellen's chart, $10-20 \mathrm{mmHg}$ of intraocular pressure, $+/-3.00$ diopters of refractive values and optical coherence tomography measurements were received. Statistical data was analyzed with a IBM SPSS 21; software program. Independent sample t-test was used to compare macular thickness between age groups and to analyze sex related changes and to compare retinal thicknesses across sectors. Two-way variance analysis was used to compare gender differences in age groups in central foveal thickness.

Results: Central foveal thickness was significantly thicker in men than in women $(p=0.001)$. There was no significant change in central foveal thickness with age $(p=0.068)$. Among age and gender groups; total peripapillary retinal nerve fiber layer thickness, retinal nerve fiber layer thickness in superior and inferior quadrant, optic disc cup and disc areas, and cup / disc ratio were not significantly changed.

Conclusion: Significant changes were observed in retinal layers depending on the age and sex. Therefore, these results must be considered when analyzing the retina associated with both systemic and retinal disease.
\end{abstract}

Key Words: Optic coherance tomography, age related macular thickness, retinal nerve fiber layer.

Ongun GT. Effect of age and sex on retinal layers thickness in normal eyes. Pam Med J 2019;12:41-48. 


\section{Giriş}

Retina kalınlığı, retina ve optik disk hastalıklarının tanısında ve tedaviye yanıtında önemlidir. Normal gözlerde retina tabakalarının kalınlığını gösteren önceki çalışmalarda yaş ve cinsiyete göre makula kalınlıklarında bölgesel değişiklikler saptanmıştır [1, 2, 3]. Ayrıca genetik ve çevresel faktörler ile birlikte yaşa bağlı olarak makulanın işlevi, kan akımı ve kalınlığı değişerek merkezi görüşün geri dönüşümsüz kaybı ile sonuçlandığı gösterilmiştir [4, 5, 6, 7]. Kadınlarda yaşa bağlı makula dejenerasyonu ve idiyopatik makula deliklerinin daha sık görüldüğü birkaç çalışma olması normal ve hasta gözlerde cinsiyet farklılığının önemli olabileceğini işaret etmektedir [8, 9, 10]. Yine de kadınlarda hem cinsiyete özgü cinsiyet hormonları hem de yaşa bağlı hormonal değişiklikler makula fonksiyonunu etkilese de östrojenin makula üzerine etkisi tam bilinmemektedir [11, 12].

Makula ve retinal sinir lifi tabakası kalınlığı ölçümleri invaziv olmayan, yüksek çözünürlük ve kalitede spektral Optik Koherans Tomografi (OKT) ile yapılabilmektedir [13, 14]. Birçok OKT çalışmasında normal gözlerde yaşa bağlı total retina tabakası kalınlığında 'Erken Tedavi Diyabetik Retinopati Çalışması (ETDRS)' perisantral ve periferal makuler bölge sınıflamasına göre anlamlı bir azalma tespit edilmiştir [15-18].

$\mathrm{Bu}$ çalışmanın amacı normal gözlerde ETDRS sınıflamasına göre makula bölgeleri ve peripapiller retinal sinir lifi kalınlığının yaş ve cinsiyet ile ilişkisini OKT ölçümleri ile değerlendirmektir. Yaş ve cinsiyetin retina kalınlığına etkisi üzerine elde edilen veriler ile retina hastalıklarının tanı ve tedavisinde yardımcı olması hedeflenmiştir.

\section{Gereç ve yöntem}

$\mathrm{Bu}$ retrospektif, kesitsel çalışmada 2017 Şubat ve 2018 Ocak tarihleriarası göz hastalıkları kliniğimize kontrol amacıyla başvuran sağlıklı 500 kişinin 500 gözü çalışmaya alındı. Çalışma protokolü etik kurul onayı alındıktan sonra Helsinki deklerasyonuna göre oluşturuldu. Çalışmaya herhangi bir göz hastalığı (katarakt, glokom, üveit, retina hastalıkları. vb) olmayan ya da daha önce oküler cerrahi geçirmeyen ve retinayı etkileyebilecek kronik sistemik hastalığı (diyabet, hipertansiyon, romatoid artirit, HIV vb) olmayan 18-96 yaş arası erişkin bireyler dahil edildi. Çalışmaya düzeltilmiş en iyi görme keskinliği Snellen eşeline göre $20 / 20$, göz içi basıncı havalı tonometre ile 10$20 \mathrm{mmhg}$ arasında, refraktif değerleri $+/-3,00$ dioptri aralığında olan gözler alındı. Poliklinik kayıtlarından tüm olguların yarıklı lamba biyomikroskop ve 90D temassız lens ile tam bir oftalmolojik muayene sonuçları ve 3D OCT-1 Maestro (Topcon, Tokyo, Japonya) ile pupilla dilatasyonu aranmaksızın yapılan OKT ölçümleri alındı. 3D OCT-1 Maestro saniyede yaklaşık 50.000 A-tarama hızında, $6,0 \mathrm{~mm}$ $1024 \times 12$ bir alanda makulayı ve $6,0 \times 6,0 \mathrm{~mm}-$ $512 \times 128$ bir alanda optik siniri taramaktadır (Şekil 2, 3). Bu ölçüm birçok maküler ve optik sinir bozukluğunun teşhis ve takibinde yararlıdır. OKT ile yapılan ölçümlerin bilinen hiçbir yan etkisi yoktur, radyasyon içermemektedir, göze direkt olarak temas etmemektedir, konforu bozmamaktadır. Ölçümler sırasında hastalara ilaç uygulaması yapılmamakta ve herhangi bir girişimsel işlem uygulanmamaktadır. Her çekim deneyimli tek bir kullanıcı tarafından yapılmakta ve görüntü kalite faktörü $>60$ olan görüntüler alınmaktadır.

Ortalama maküler kalınlık ve hacimlerinin otomatik olarak ölçülmesi, ETDRS kadranlarına göre 9 ayrı alanda yapıldı. Buna göre fovea; $1 \mathrm{~mm}$ çapında merkezi daire, perisantral halka; $1 \mathrm{~mm}$ iç $3 \mathrm{~mm}$ dış çapındaki halka, periferal halka ise $3 \mathrm{~mm}$ iç $6 \mathrm{~mm}$ dış çapındaki en dıştaki halkadır (Şekil 1). Retina tabaka kalınlık haritasından veriler, Erken Tedavi Diyabetik Retinopati Çalışması'nda tanımlanan 3 eşmerkezli daire içinde 9 maküler sektörde gruplandırılmıştır [15]. Santral foveal kalınlık, perisantral ve periferal halkaların kalınlığı ve retinal siniri lifi tabakası kalınlığı 4 kadranda [üst, alt, nazal, temporal] ayrı ayrı değerlendirilmiştir.

İstatistiksel veriler IBM SPSS 21; SPSS Inc. Chicago, yazılım programı ile analiz edildi. $P$ değeri $<0,05$ istatistiksel olarak anlamlı kabul edildi. Makula kalınlığını 18-55 yaş grubu ile 56 yaş ve üstü grubu arasında karşılaştırmak için bağımsız örneklem $t$ testi kullanıldı. Cinsiyet ilişkili değişiklikleri analiz etmek ve sektörler arasındaki retina kalınlıklarını karşılaştırılmak için bağımsız örneklem t testi kullanıldı. Santral foveal kalınlıkta genç ve daha yaşı gruplarda cinsiyet farklılıklarını karşılaştırmak için iki yönlü varyans analizi kullanıldı. Kadın ve erkeklerin yaş ortalamaları arasındaki farklılıkları değerlendirmek için ki kare testi kullanıldı. 


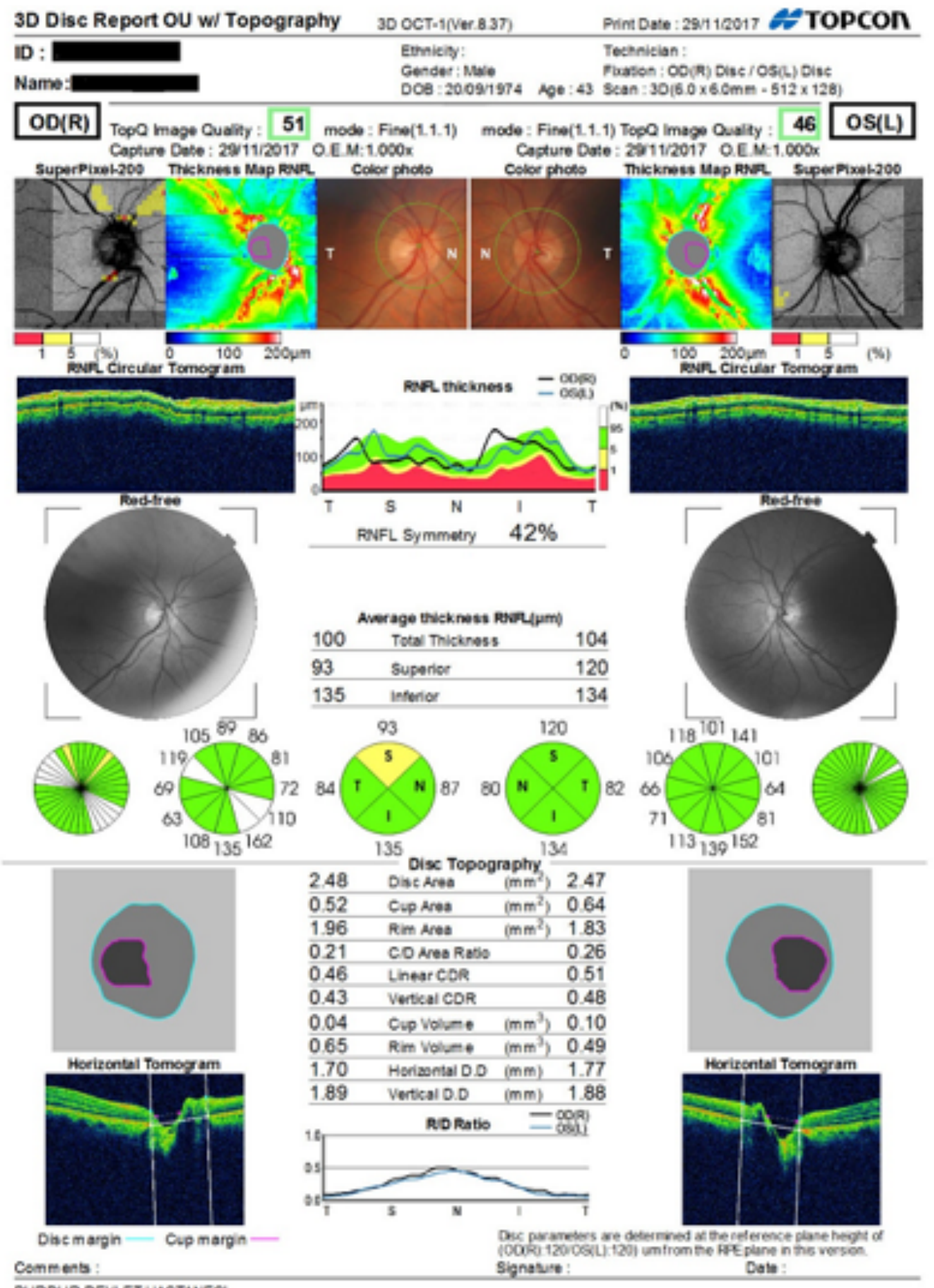

BURDUR DEVLET HASTANESI

Şekil 2. Optik koherans tomografi ile retina sinir lifi tabakası analizi 


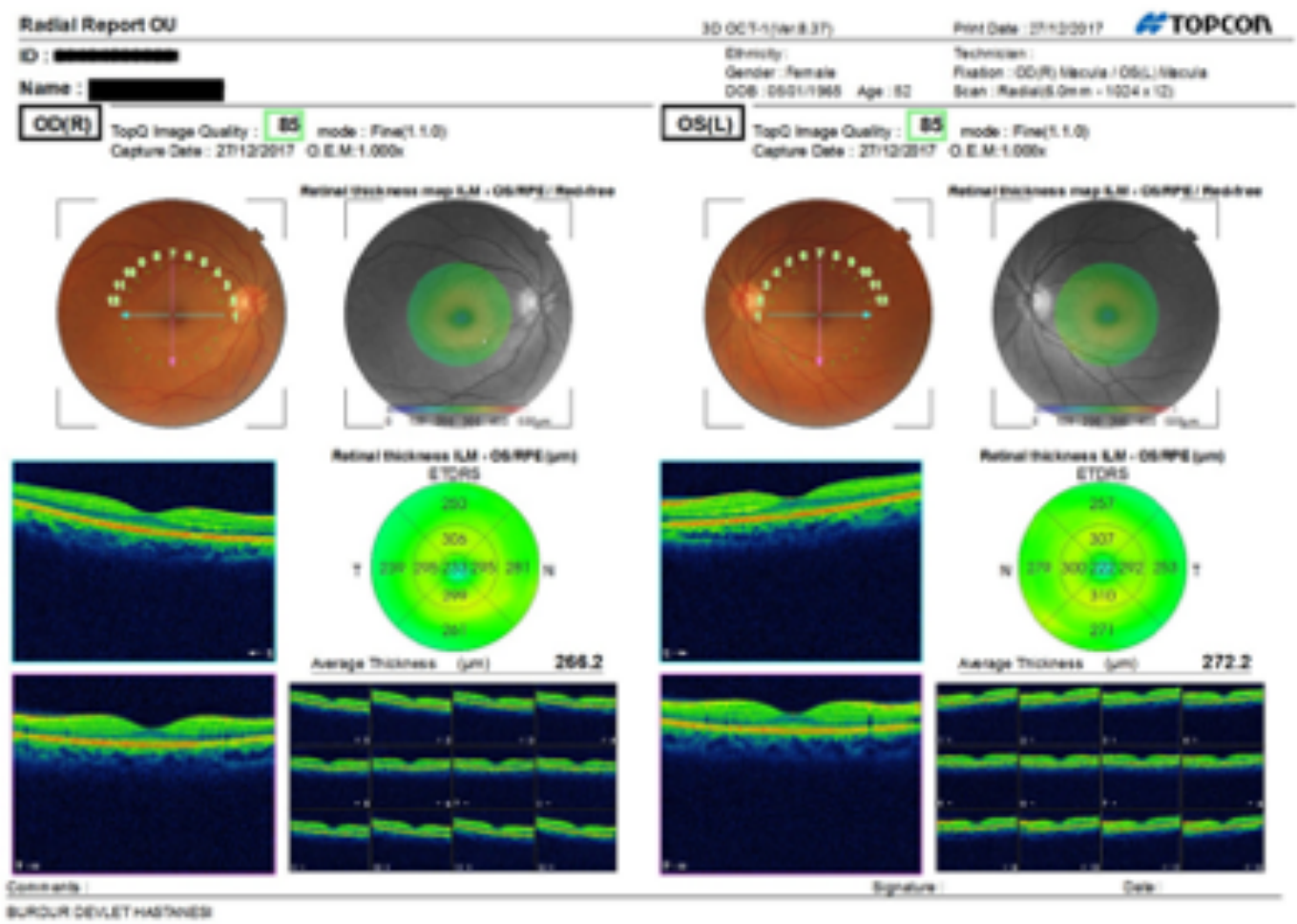

Şekil 3. Optik koherans tomografi ile makuler kalınlık analizi

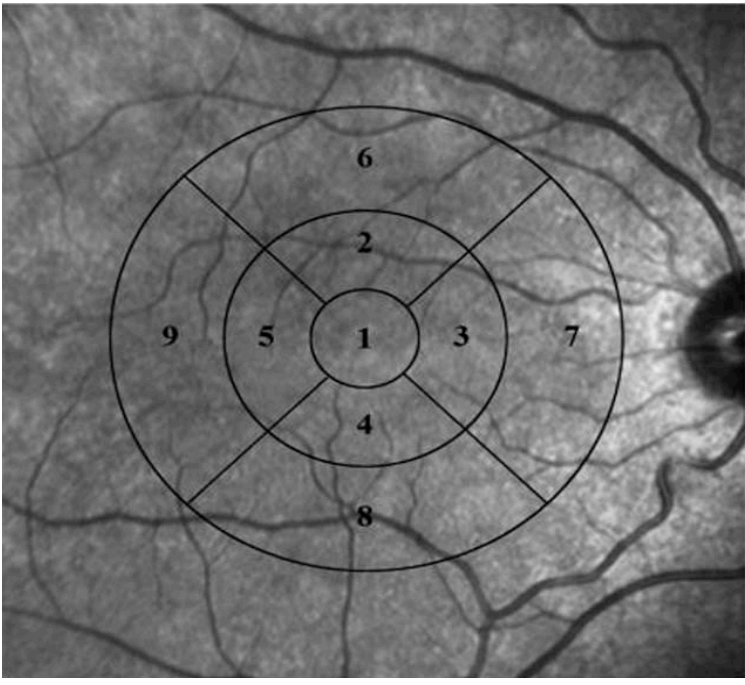

Şekil 1. Optik koherans tomografide Erken tedavi diyabetik retinopati çalışması. (ETDRS) bölgeleri. Fovea (1); perisantral halka (2-5); ve periferik halka (bölgeleri 6-9)

\section{Bulgular}

Çalışmaya alınan 500 kişinin 247’si kadın 253‘ü erkekti. Bireyler minimum 18 yaş, maksimum 96 yaş idi. Yaş ortalaması 18-55 yaş grubunda 36,55 yaş üstü grupta 62 bulundu. Çalışmadaki kadınların \%47,8'i 18-55 yaş arası, \%52,2‘si 55 yaş üstü gruptadır. Erkeklerin \%51,8'i 18-
55 yaş arası, \%48,2 'si 55 yaş üstü gruptadır. Pearson ki kare testine göre kadın erkek dağılımı dengelidir, kadınların yaş ortalamaları erkeklerin yaş ortalamalarına göre anlamlı olarak daha azdır $(p=0,001)$. 18-55 yaş grubu ile 56 yaş ve üstü grubu karşılaştırıldığında yaşla birlikte santral fovea kalınlığında anlamlı bir değişiklik saptanmadı $(p=0,068)$. ETDRS'ye göre perisantral halkada temporal ve üst sektör kalınlıklarında yaşa bağlı anlamlı incelme görüldü (sırasıyla $p=0,021, p=0,002$ ). Periferal halkada ise temporal, nazal ve üst kadranda yaşa bağlı anlamlı incelme saptanmıştır (sırasıyla $p=0,035$, $p=0,016, p=0,012)$.

Santral foveal kalınlık erkeklerde kadınlara göre anlamlı olarak daha kalın saptandı $(p=0,001)$. 18-55 yaş kadınlarda santral foveal kalınlık ortalama 218 mikron, erkeklerde ortalama 228 mikron saptandı. 56 yaş ve üstü grupta kadınlarda ortalama santral foveal kalınlık 221 mikron, erkeklerde 232 mikron saptandı. ETDRS'ye göre perisantral halkada nazal, temporal ve alt sektör kalınlıkları da anlamlı olarak erkeklerde daha kalın görüldü (sırasıyla $p=0,001, p=0,001, p=0,037$ ). Periferal halkadaki sektörlerde ise kadın ve erkek grubu arasında anlamlı farklılık görülmedi. Yaş grupları arasında santral foveal kalınlıkta anlamlı bir farklılık saptanmazken perisantral halkanın üst ve temporal sektörü genç yaş grubunda anlamlı 
olarak daha kalın ölçülmüştür (sırasıyla $p=0,002$, $p=0,021$ ) (Tablo 1). Periferal halkada ise üst, nazal ve temporal sektörler genç yaş grubunda anlamlı olarak daha kalın çıkmıştır (sırasıyla $p=0,012, p=0,016, p=0,035)$. Nazal, temporal, üst ve alt sektörler ayrı ayrı karşılaştırıldığında ise perisantral halka periferal halkaya göre her birinde anlamlı olarak daha kalın saptanmıştır $(p=0,001)$. Ayrıca hem perisantral hem periferal halkada üst sektör alt sektörden, nazal sektör temporal sektörden anlamlı olarak daha kalın saptanmıştır $(p=0,001)$. Santral foveal kalınlıkta hem genç yaş grubunda hem de daha yaşlı olan grupta cinsiyetler arası anlamlı bir farklılık görülmedi.

Yaş ve cinsiyet grupları arasında; total peripapiller retina sinir lifi tabakası kalınlığı, üst ve alt kadran retinal sinir lifi tabakası kalınlığı, optik disk çukurluk ve disk alanları ile çukurluk/disk oranında da anlamlı bir değişiklik görülmemiştir. Retinal sinir lifi tabakası kalınlığı alt kadranda üst kadrana göre anlamlı olarak daha kalın saptanmıştır ( $p=0,001)$ (Tablo 2).

\section{Tartışma}

Çalışmamız bölgemizde makula ve retina sinir lifi tabakası kalınlığına yaş ve cinsiyetin etkisini değerlendirme amacıyla yapılan bilgimize göre en fazla sayıda birey katılımı olan çalışmadır. Daha önce normal popülasyonda makula kalınlığı ve retinal sinir lifi kalınlığını ölçen çalışmalar vardır [17-19]. Ancak bilgimize göre bu sayıda birey katılımı ile çukurluk, disk alanları ile çukurluk/disk oranlarını da dahil ederek yaş ve cinsiyet açısından retina kalınlığını değerlendiren bir çalışma yoktur.

Retinal tabakaların kalınlık haritalaması retinal patolojilerinin tespit edilmesi ve izlenmesi için yararlı olabilir. Bu amaçla yapılmış birçok çalışmada bizim çalışmamızda olduğu gibi yaş ile santral foveal kalınlık arasında bir ilişki saptanmamıştır [20-23]. Bununla birlikte Kanai ve ark. [24] Manassalorn ve ark. [25] ve Appukuttan ve ark. [26] çalışmaları her retinal ETDRS bölgesi ile santral bölge ve yaş arasında negatif korelasyon göstermiştir. Daha önceki çalışmalarda yaş ile anlamlı fark bulunmaması incelenen deneklerin az sayıda olmasına bağlanmıştır. Bizim çalışmamıza dahil edilen kişi

Tablo 1:ETDRS ‘ye göre makula 9 kadranın OKT ölçümlerine göre kalınlığının yaş gruplarına göre karşılaştırılması

\begin{tabular}{|c|c|c|c|c|c|}
\hline & Yaş & $N=500$ & $\begin{array}{c}\text { Ortalama } \\
\text { (mikron) }\end{array}$ & ss & $\mathbf{P}$ \\
\hline \multirow{2}{*}{$\begin{array}{l}\text { Perisantral } \\
\text { temporal }\end{array}$} & $18-55$ & 249 & 285,2410 & 17,60150 &, 021 \\
\hline & 56 ve üstü & 251 & 281,4582 & 18,87096 & \\
\hline \multirow{2}{*}{$\begin{array}{c}\text { Perisantral } \\
\text { nazal }\end{array}$} & $18-55$ & 249 & 295,1928 & 20,43407 & ,106 \\
\hline & 56 ve üstü & 251 & 292,3028 & 19,44870 & \\
\hline \multirow{2}{*}{$\begin{array}{l}\text { Periferal } \\
\text { temporal }\end{array}$} & $18-55$ & 249 & 248,3815 & 17,33409 &, 035 \\
\hline & 56 ve üstü & 251 & 244,9084 & 19,27806 & \\
\hline \multirow{2}{*}{ Periferal nazal } & $18-55$ & 249 & 276,6586 & 17,03767 &, 016 \\
\hline & 56 ve üstü & 251 & 272,7371 & 19,11237 & \\
\hline \multirow{2}{*}{ Perisantral üst } & $18-55$ & 249 & 300,2369 & 17,42276 & ,002 \\
\hline & 56 ve üstü & 251 & 295,2191 & 19,36295 & \\
\hline \multirow{2}{*}{ Perisantral alt } & $18-55$ & 249 & 294,8996 & 17,47192 & ,089 \\
\hline & 56 ve üstü & 251 & 292,2072 & 17,84480 & \\
\hline \multirow{2}{*}{ Periferal üst } & $18-55$ & 249 & 259,0402 & 15,49839 & ,012 \\
\hline & 56 ve üstü & 251 & 254,8566 & 20,96901 & \\
\hline \multirow{2}{*}{ Periferal alt } & $18-55$ & 249 & 254,5462 & 15,63362 & ,066 \\
\hline & 56 ve üstü & 251 & 251,8207 & 17,39551 & \\
\hline \multirow{2}{*}{ Santral fovea } & $18-55$ & 249 & 223,0884 & 20,56403 &, 068 \\
\hline & 56 ve üstü & 251 & 226,5100 & 21,26544 & \\
\hline
\end{tabular}

SS: Standart Sapma ETDRS: Erken Tedavi Diyabetik Retinopati Çalışması OKT: Optik Koherans Tomografi 
Tablo 2 : Retinal sinir lifi tabakası kalınlığı ve optik disk parametrelerinin cinsiyetler ile korelasyonu

\begin{tabular}{cccccc}
\hline & Cinsiyet & N=500 & Ortalama & SS & P \\
\hline \multirow{2}{*}{ Total RSLT } & Kadın & 247 & 97,6235 & 9,39901 &, 912 \\
& Erkek & 253 & 97,7194 & 9,88888 &, 912 \\
\multirow{2}{*}{ RSLT üst } & Kadın & 247 & 117,3887 & 15,37005 &, 914 \\
& Erkek & 253 & 117,2372 & 16,02376 &, 914 \\
RSLT alt & Kadın & 247 & 119,6721 & 15,28755 &, 905 \\
& Erkek & 253 & 119,8340 & 14,92774 &, 905 \\
Çukurluk Alan & Kadın & 247 & 1,0628 & 3,92778 &, 259 \\
& Erkek & 253 &, 7812 &, 53179 &, 265 \\
Rim Alan & Kadın & 247 & 1,5738 &, 41650 &, 577 \\
& Erkek & 253 & 1,5946 &, 41686 &, 577 \\
C/D oranı & kadın & 247 &, 3238 &, 16973 &, 602 \\
\hline
\end{tabular}

SS: Standart Sapma RSLT: Retinal siniri lifi tabakası C/D: Çukurluk/Disk

sayısı 500 olmakla birlikte yaş ile santral foveal kalınlık arasında bir korelasyon saptanmadı. Ancak perisantral halkada temporal ve üst sektör kalınlıklarında yaşa bağlı anlamlı incelme gösterildi.

Staurenghi $G$ ve ark. [27] bir çalışması, yaşla birlikte ortaya çıkan retina pigment epitel tabakasının yapısal değişiklikler ve melanin granüllerinin kaybı, lipofusin birikmesi ile birlikte kalınlaşmış Bruch membranına bağlı olarak santral foveal kalınlığın yaşla birlikte önemli ölçüde artabileceğini göstermiştir. Bizim çalışmamızda ise, santral foveal kalınlık yaşla birlikte belirgin farklılık göstermedi. Sadece perisantral ve periferal halkada bazı sektörlerde genç yaş grubunda daha kalın gösterilmiştir. $\mathrm{Bu}$ çalışmalarda dikkat edilmesi gereken bir nokta da farklı ülkeler ve bölgelerde yapılmaları nedeniyle ırksal olarak da sonuçların farklılık gösterebileceğidir.

Önceki çalışmalar, toplam maküla kalınığında veya bazı sektörlerin kalınlıklarında cinsiyete bağlı farklılıklar göstermiştir [2, 23, 28]. Nieves-Moreno Mve ark. [19], ile Grover $S$ ve ark. [29] çalışmalarında, santal foveal kalınlık erkeklerde kadınlara göre anlamlı olarak daha kalın ve perisantral halkanın tüm sektörleri ve periferik halkanın temporal sektör kalınlığı erkeklerde kadınlardan anlamlı derecede daha fazla saptanmıştır. Bizim çalışmamızda da erkeklerde santral foveal kalınlık ve perisantral halkanın nazal, temporal ve alt sektörleri daha kalın saptandı $(p=0,001)$.
Retina kalınlıkları sektörler arasında da kendi içinde farklılıklar göstermektedir. Tüm gruplarda retinal sinir lifi tabakası alt kadranda üst kadrana göre anlamlı olarak daha kalın olduğu görüldü. Ayrıca makulanın hem perisantral hem periferal halkasında üst sektör alt sektörden, nazal sektör temporal sektörden anlamlı olarak daha kalın saptandı $(p=0,001)$. Benzer çalışmalar da nazal kadranda total retina kalınlığının temporal kadranda daha fazla olduğunu ve perisantral halkada periferik halkadan daha fazla olduğunu göstermiştir [30-39].

Çalışmamız diğer popülasyonlardaki varyanslar ve OKT cihazlarının türüne göre bazı farklılıklar göstermekle beraber, daha önce bildirilmiş olan diğer spektral alan OKT çalışmalarına benzer sonuçlar içermektedir [30-32]. Ayrıca ek olarak incelediğimiz total peripapiller retina sinir lifi tabakası kalınlığı, üst ve alt kadran retinal sinir lifi tabakası kalınlığı, optik disk çukurluk ve disk alanları ile çukurluk/disk oranında da yaş ve cinsiyet grupları arasında anlamlı bir korelasyon tespit edilmemiştir.

Çalışmamızın belli başlı kısıtlıı̆̆ı katılımcıların tümünün Türkiye'nin güney ve güneybatı bölgesinden olmasıdır. Günümüzde OKT çözünürlüğü retina kalınlığındaki 4 um'deki farklıııları yakalayamadığından, bu çalışmada bulunan kalınlık değişikliklerinin gelecekte daha hassas bir teknoloji ile belirlenebilmesi gerekecektir. 
Ayrıca retina tabakalarının optik özelliklerinde lokal değişikliklere neden olan retinal patolojilerin varlığında spektral alan OKT ile retinal kalınlık haritalaması sınırlı olabilir.

Sonuçolarak; buçalışmayaşvecinsiyete bağlı olarak çeşitli retinal tabakaların kalınlıklarında farklılıklar olduğunu göstermektedir. Bu nedenle, bu bulgular hem sistemik hem de retinal hastalıklarla ilişkili retinal tabaka kalınlığını analiz ederken kullanılabileceği gibi yaşlanma için objektif bir parametre sağlamak için basit bir yöntem olarak da kullanılabilir.

Çıkar İlişkisi: Yazar çıkar ilişkisi olmadığını beyan eder.

\section{Kaynaklar}

1. Neuville JM, Bronson-Castain K, Bearse MA Jr, et al. OCT reveals regional differences in macular thickness with age. Optom Vis Sci 2009;86:E810.

2. Song WK, Lee SC, Lee ES, Kim CY, Kim SS. Macular thickness variations with sex, age, and axial length in healthy subjects: a spectral domain-optical coherence tomography study. Invest Ophthalmol Vis Sci 2010;51:3913-3918.

3. Sung KR, Wollstein G, Bilonick RA, et al. Effects of age on optical coherence tomography measurements of healthy retinal nerve fiber layer, macula, and optic nerve head. Ophthalmology 2009;116:1119.

4. Bonnel S, Mohand-Said S, Sahel JA. The aging of the retina. Exp Gerontol 2003;38:825-831.

5. Grunwald JE, Piltz J, Patel N, Bose S, Riva CE. Effect of aging on retinal macular microcirculation: A blue field simulation study. Invest Ophthalmol Vis Sci 1993;34:3609-3613.

6. Xu HP, Chen M, Forrester JV. Para-inflammation in the aging retina. Prog Retin Eye Res 2009;28:348-368.

7. Kaur I, Ghanekar Y, Chakrabarti S. Understanding the genetics of agerelated macular degeneration: Some insights into the disease pathogenesis. International Journal of Human Genetics 2008;8:161-169.

8. Gupta PD, Johar K, Nagpal K, Vasavada AR. Sex hormone receptors in the human eye. Surv Ophthalmol 2005; $50: 274-284$.

9. Feskanich D, Cho E, Schaumberg DA, Colditz GA, Hankinson SE. Menopausal and reproductive factors and risk of age-related macular degeneration. Arch Ophthalmol 2008;126:519-524.

10. Evans JR, Schwartz SD, McHugh JDA, et al. Systemic risk factors for idiopathic macular holes: A case-control study. Eye 1998;12:256-259.
11. Eisner A, Toomey MD. The color appearance of stimuli detected via short-wavelength-sensitive cones: Comparisons with visual adaptation and visual field data for peri- or post-menopausal women under 70 years of age. Vision Res 2008;48:2663-2672.

12. Jagle $H$, Heine $J$, Kurtenbach $A$. L:M-cone ratio estimates of the outer and inner retina and its impact on sex differences in erg amplitudes. Doc Ophthalmol 2006;113:105-113.

13. Bagci AM, Shahidi M, Ansari R, Blair M, Blair NP, Zelkha R. Thickness profiles of retinal layers by optical coherence tomography image segmentation. Am J Ophthalmol 2008;146:679-687.

14. Garvin MK, Abramoff MD, Kardon R, Russell SR, Wu X, Sonka M. Intraretinal layer segmentation of macular optical coherence tomography images using optimal 3-D graph search. IEEE Trans Med Imaging 2008;27:1495-1505.

15. Early Treatment Diabetic Retinopathy Study design and baseline patient characteristics. ETDRS report number 7. Ophthalmology 1991;98:741-756.

16. Alamouti B, Funk J. Retinal thickness decreases with age: an OCT study. Br J Ophthalmol 2003;87:899-901.

17. Duan XR, Liang YB, Friedman DS, et al. Normal macular thickness measurements using optical coherence tomography in healthy eyes of adult Chinese persons: the Handan Eye Study. Ophthalmology 2010;117:15851594.

18. Eriksson U, Alm A. Macular thickness decreases with age in normal eyes: a study on the macular thickness map protocol in the Stratus OCT. Br J Ophthalmol 2009;93:1448-1452.

19. Nieves-Moreno M, Martínez-de-la-Casa JM, MoralesFernández L, Sánchez-Jean R, Sáenz-Francés F, García-Feijoó J. Impacts of age and sex on retinal layer thicknesses measured by spectral domain optical coherence tomography with Spectralis. PLoS One 2018;13:e0194169.

20. Chan A, Duker JS, Ko TH, Fujimoto JG, Schuman JS. Normal macular thickness measurements in healthy eyes using stratus optical coherence tomography. Arch Ophthalmol 2006;124:193-198.

21. Falsini B, Ziccardi L, Stifano G, et al. Temporal response properties of the macular cone system: Effect of normal aging and age-related maculopathy. Invest Ophthalmol Vis Sci 2007;48:4811-4817.

22. Wong ACM, Chan CWN, Hui SP. Relationship of gender, body mass index, and axial length with central retinal thickness using optical coherence tomography. Eye 2005;19:292-297.

23. Kelty PJ, Payne JF, Trivedi RH, Kelty J, Bowie EM, Burger BM. Macular thickness assessment in healthy eyes based on ethnicity using stratus oct optical coherence tomography. Invest Ophthalmol Vis Sci 2008:49:2668-2672. 
24. Kanai K, Abe T, Murayama K, Yoneya S. Retinal thickness and changes with age. Nippon Ganka Gakkai Zasshi 2002;106:162-165.

25. Manassakorn A, Chaidaroon W, Ausayakhun S, Aupapong S, Wattananikorn S. Normative database of retinal nerve fiber layer and macular retinal thickness in a Thai population. Jpn J Ophthalmol 2008;52:450-456.

26. Appukuttan B, Giridhar A, Gopalakrishnan M, Sivaprasad S. Normative spectral domain optical coherence tomography data on macular and retinal nerve fiber layer thickness in Indians. Indian J Ophthalmol 2014;62:316-321.

27. Staurenghi G, Sadda S, Chakravarthy U, Spaide RF. Proposed lexicon for anatomic landmarks in normal posterior segment spectral-domain optical coherence tomography: the IN•OCT consensus. Ophthalmology 2014;121:1572-1578.

28. Huang J, Liu X, Wu Z, Xiao H, Dustin L, Sadda S. Macular thickness measurements in normal eyes with time-domain and Fourier-domain optical coherence tomography. Retina 2009;29:980-987.

29. Grover S, Murthy RK, Brar VS, Chalam KV. Comparison of retinal thickness in normal eyes using Stratus and Spectralis optical coherence tomography. Invest Ophthalmol Vis Sci 2010;51:2644-2647

30. Leung CK, Cheung CY, Weinreb RN, et al. Comparison of macular thickness measurements between time domain and spectral domain optical coherence tomography. Invest Ophthalmol Vis Sci 2008;49:48934897.

31. Kakinoki M, Sawada O, Sawada T, Kawamura H, Ohji M. Comparison of macular thickness between Cirrus HD-OCT and Stratus OCT. Ophthalmic Surg Lasers Imaging 2009;40:135-140

32. Sull AC, Vuong LN, Price LL, et al. Comparison of spectral/Fourier domain optical coherence tomography instruments for assessment of normal macular thickness. Retina 2010;30:235-245.

33. Chan A, Duker JS, Ko TH, Fujimoto JG, Schuman JS. Normal macular thickness measurements in healthy eyes using Stratus optical coherence tomography. Arch Ophthalmol 2006;124:193-198.

34. Lam DS, Leung KS, Mohamed S, et al. Regional variations in the relationship between macular thickness measurements and myopia. Invest Ophthalmol Vis Sci 2007;48:376-382.

35. Kelty PJ, Payne JF, Trivedi RH, Kelty J, Bowie EM, Burger BM. Macular thickness assessment in healthy eyes based on ethnicity using Stratus OCT optical coherence tomography. Invest Ophthalmol Vis Sci 2008;49:2668-2672.

36. Eriksson U, Alm A. Macular thickness decreases with age in normal eyes: a study on the macular thickness map protocol in the Stratus OCT. Br J Ophthalmol 2009;93:1448-1452.
37. Legarreta JE, Gregori G, Punjabi OS, Knighton RW, Lalwani GA, Puliafito CA. Macular thickness measurements in normal eyes using spectral domain optical coherence tomography. Ophthalmic Surg Lasers Imaging 2008;39:43-49.

38. Grover S, Murthy RK, Brar VS, Chalam KV. Normative data for macular thickness by high-definition spectraldomain optical coherence tomography (spectralis). Am J Ophthalmol 2009;148:266-271.

39. Ooto S, Hangai M, Sakamoto A, et al. Threedimensional profile of macular retinal thickness in normal Japanese eyes. Invest Ophthalmol Vis Sci 2010;51:465-473. 